Daniel GutiÉRREZ V.*

\title{
FIGURAS DEL SUJETO
}

Questa selva selvaggia e aspra e forte Che nel pensier rinova la paura!

Dante, Inferno.

\section{Resumen}

En el presente artículo se confrontan las proposiciones de Touraine y Lacan en torno al sujeto, partiendo de un breve recuento de lo que dijo el a crítica estructuralismo ta respecto al tema. El punto de vista que aquí se sostiene es el del psicoanálisis y el objetivo es mostrar los límites del pensamiento sociológico sobre en el tema del sujeto y su constitución.". Pero,, ¿podría atribuirse este fracasoe f racaso a una simple inadecuación de las categorías sociológicas para pensar el sujeto? ¿O es algo particular al enfoque de Touraine, incluso si el suyo es el más elaborado esfuerzo por entender el proceso social como resultante de la acción del sujeto en acto obra en el movimiento social? Tal vez la falla la falla del pensamiento sociológico respecto al sujeto revela algo más profundo, algo que podría interpretarse como un obstáculo epistemológico, como un síntoma que insiste y que está aún por a tratar. La hipótesis que se expone es que la Sociología errará su sujeto si no se redefine como disciplina que considera la acción del lenguaje y el discurso en la constitución de los sujetos en la sociedad y de los nexos que los unen. En ese caso, sin embargo, el "sujeto sociológico" vendría a ser idéntico al sujeto del significante postulado por Lacan.

Palabras clave: Sujeto, psicoanálisis, sociología, lenguaje.

\section{Abstract}

In the present work the propositions of Touraine and Lacan are confronted around the subjet, beginning from a brief recount of the estructuralis said about the topic. The point of view that it is sustained here is that of the psychoanalysis and the objective is to show the limits of the sociological thought on the subjet and its constitution.

\footnotetext{
* Ph. D. en Ciencias Sociales, New School for Social ResearchSociología - tlon@hotmail.com
} 
But, could this failure be attributed to a simple inadequacy of the sociological categories to think the subject? Or is something peculiar to the focus of Touraine, even if his is the elaborated effort to understand the social process a result of the subject action in act in the social movement? Perhaps the lack of the sociological thought regarding the subject reveals something deeper, something that could be interpreted as an epistemological obstacle, as a symptom that insists and that is still to try. The hypothesis that is exposed is that the Sociology will miss its subject if it is not redefined like discipline that considers the action of the language and the speech in the constitution of the subject in the society and in the connections that unite them. In that case, however, the "sociological" subject would come to be identical to the subject of the significant postulated by Lacan.

Key words: Subject, psychoanalysis, sociology, languaje.

\section{Introducción}

Pese a que el estructuralismo francés lo declarara irremisiblemente "muerto".

Aunque el estructuralismo francés lo declaró irremisiblemente "muerto,", el sujeto parece haber revivido en nuestros días como tema de reflexión sociológica. Como "sujeto colectivo", o encarnado en "actor", individual, el sujeto está de regreso a las ciencias sociales, particularmente a la Sociología, donde ha consolidado su estatuto como categoría central del análisis de la acción social ${ }^{1}$.

Este revival del sujeto es, en parte, consecuencia de la reflexión de Alain Touraine, quien ha argumentado ampliamente a favor del "retorno del actor" al pensamiento sociológico, criticando su asimilación dentro de las estructuras del sistema social. Touraine ha emprendido así la construcción de una teoría del sujeto en sociedad que brinda soporte a una consideración del "ac-

\footnotetext{
${ }^{1}$ Como ha escrito Ernesto Laclau, "Tal vez la muerte del sujeto ha sido la condición previa al presente y renovado interés en el tema de la subjetividad. Es quizás la imposibilidad de referir la concreta y finita expresión de una variada subjetividad a un centro trascendental lo que hace posible concentrar nuestra atención en la multiplicidad misma. Los gestos fundadores de los sesenta están todavía entre nosotros, haciendo posible las exploraciones teóricas y políticas en las cuales hoy estamos envueltos" (Laclau, 1996: 20). La traducción de esta cita y de las que siguen es mía.
}

tor social" liberada de todo sesgo empirista o funcionalista. Según su esta óptica, si hay "actores" en la sociedad no es simplemente porque grupos e individuos son protagonistas de procesos sociales y políticos, sino porque los actores son ante todo sujetos. De paso, con sus ideas, Touraine ha sentado las bases de construcción del "sujeto de la Sociología", cuya particularidad es la de ser un sujeto colectivo, i. e., el "movimiento social" nacido del conflicto por el cual la sociedad se produce a sí misma, es decir, un sujeto en obra en el "movimiento social".

Se podría aducir, sin embargo, que el sujeto nunca fue realmente expulsado de la Sociología. De una manera u otra, siempre habría estado presente en sus dominios, cubierto bajo el manto fenomenológico del individuo que construye intersubjetivamente el sentido de sus prácticas dentro del Lebenswelt (Schütz, 1967; Berger y Luckmann, 1966). O bajo especie de self, como en Cooley (1964) y Mead (1962). O como "actor" en Parsons (1937), en donde equivale más bien a la estructura. O, también, como el "interacting individual" de Blumer (1969) y el "dramaturgical performer" de Goffman (1973), que son la imagen misma del actor sin sistema. Pero aunque es posible decir que todas estas formulaciones son tributarias de cierta idea de sujeto, como tal, la noción de sujeto -colectivo o individual- nunca fue sistematizada allí. En general, el "actor" al que estas teorías refieren es un individuo captado de manera intuitiva y desde el sentido común, no construido teóricamente. Se trataEs, por lo tanto, de un pseudo actor, sociológicamente indeterminado porque su acción no se inscribe en relaciones sociales, sino en sus intereses y expectativas, en estrategias de juego político, en relaciones de dominación, etc.

Por el contrario, el sujeto de Touraine no es un dato empírico ni una entidad positiva o sustancial, sino un principio ético de orden no social que se arraiga en las relaciones asimétricas entre actores. De hecho, hasta Touraine, la Sociología parece no haber tenido necesidad de una teoría del sujeto que preste dé sustento a una concepción del actor en la que este no se vea reducido al sentido y la performance, ni se piense como mero agente de los campos de fuerza sociales, de las estructuras económicas o de la interacción. Creo por ello fundado entender el esfuerzo de Touraine como la construcción de un sujeto propiamente sociológico.

El "sujeto de la Sociología" que se perfila en el pensamiento la obra de Touraine no es el simple término de una correlación que opondría el sujeto al objeto de la Sociología (sujeto colectivo versus relaciones sociales). Su estatuto puede entenderse mejor por analogía con el sujeto de la Psicología: el sujeto de la percep- 
ción; el sujeto de la Filosofía, que es el de la razón y la consciencia; o con el sujeto del Psicoanálisis: el sujeto del inconsciente. Todas estas figuras del sujeto tienen, no obstante, al sujeto (forcluído) de la ciencia como condición, el que Descartes concibió como sujeto del cogito: sujeto definido por su conciencia, sujeto universal e indiferenciado, nunca particular. A esta formulación necesariamente remite necesariamente Touraine, aunque de manera implícita, al definir el sujeto sociológico como privado de garantes meta-sociales, como la condición no social que se expresa en las acciones de individuos y grupos ${ }^{2}$.

Aunque no cabe duda de que las propuestas de Touraine tienen una importancia fundamental para la Sociología, estas parecen no tomar en consideración las demoledoras críticas al sujeto emprendidas por los estructuralistas durante los 50s y 60s, en especial las de Lévi-Strauss y Foucault. $Y$ eso a pesar de que desde el estructuralismo en adelante ya no es posible proclamar sin más el retorno del sujeto, pretendiendo que "nada ha pasado, y no hay nada nuevo para pensar sino tal vez variaciones o modificaciones del sujeto", como lo señala de manera categórica Jean-Luc Nancy (1991: 5). Peor aún, Touraine no toma en cuenta las elaboraciones del Psicoanálisis de Jacques Lacan, aunque, ciertamente, estas representan un formidable intento por tematizar un sujeto redimido de metafísica y esencialismo, obstáculos que ya Heidegger denunciara en su Carta sobre el Humanismo (1947).

El sujeto que Lacan construye siguiendo las huellas de Freud es un efecto distintivo de la acción del significante. Este sujeto es profundamente social porque los elemen-

\footnotetext{
2 Aunque el "sujeto de la ciencia" que emerge con Descartes es condición de toda práctica científica, este es al mismo tiempo rechazado fuera de las fronteras de la ciencia, lo cual hace que la ciencia se presente como discurso sin sujeto, como una serie de enunciados impersonales.
}

tos de su constitución vienen del Otro, del registro simbólico, que es el del lenguaje, el inconsciente y la cultura $^{3}$. Pero aún siendo social, se trataes este aquí de un sujeto único, completamente singular, aunque, no precisamente porque tiene un cuerpo o se dice "yo", sino porque "lo que el lenguaje produce como inconsciente concierne a los sujetos tomados uno por uno". (Pommier, 1998: 34). Como veremos, el sujeto lacaniano, del inconsciente, es el "reverso" exacto del sujeto a la manera de à la Touraine.

\section{El estructuralismo: crónica suscinta de la muerte del sujeto}

El estructuralismo francés se destaca por su crítica radical del sujeto y su localización privilegiada en el pensamiento occidental, como sujeto de la razón, sujeto transcendental, sujeto de la historia. Desde mediados de los cincuentas, durante los sesentas y hasta comienzos de los setentas, los estructuralistas llevaron a cabo una revisión sistemática de los postulados teóricos de las ciencias sociales y "humanas", en especial en el ámbito de la Lingüística, la Antropología y el Psicoanálisis. Su crítica denunciaba vigorosamente la inspiración humanista e historicista de estas disciplinas.

Mientras que el historicismo era identificado con la filosofía de la historia de corte hegeliano-marxista, el humanismo era asimilado a la filosofía del sujeto, tanto en versión existencialista (recuérdese el pronunciamiento de 1946 de Sartre: "El existencialismo es un humanismo"), como en la reformulación fenomenológica hecha por Maurice MerleauPonty (1955). El historicismo estaba estrechamente ligado al humanismo, como filosofía de la historia, como filosofía de la praxis y como filosofía de la alienación y redención que "promet l'homme à l'homme",

\footnotetext{
3 Para la diferencia entre "Otro" y "otro," ver nota 7 .
}

como decía decía Foucault. (Foucault, 1966a. Reimpreso en Foucault, 1994: 541) La ruptura con el historicismo tomó la forma de una filosofía no dialéctica, y la predisposición anti humanista la de la "muerte del sujeto" en todos sus estados: como actor, como autor, como "el hombre" general y abstracto 4 (Dosse, 1992; Ferry y Renaut, 1985; Merquior, 1989).

Ferdinand de Saussure fue el padre proclamado del estructuralismo. La "Semiología" que Saussure creara y que él definió como la ciencia que estudia "la vida de los signos en el seno de la vida social", fue considerada en los sesenta como "ciencia líder" del conjunto de las disciplinas sociales. En gran parte, Saussure delineó el programa metodológico que estas disciplinas debían seguir para alcanzar el estatuto indiscutido de ciencias, el cual consistiría en abordar los fenómenos que estudian sociales como si fueran sistemas relacionales de signos operando en los diversos campos de la vida social (Saussure, 1980).

Para emprender el estudio del lenguaje como sistema formal de signos, Saussure tuvo que descartó ar de entrada la figura del sujeto hablante. Resistente a tomar la parole (el habla) como material idóneo adecuado para el análisis lingüístico ri-

\footnotetext{
Entre los que por aquella época adhirieron al estructuralismo se encontraban Claude Lévi-Strauss (Anthropología); Georges Dumézil (rReligiones y mitos indo-europeos); Emile Benveniste (Lingüística); Algirdas Julian Greimas (Semántica); Lucien Febvre, Fernand Braudel, Georges Duby, Jean-Pierre Vernant and Pierre Vidal-Naquet (Historia); Roland Barthes (Análisis literario); Louis Althusser (Filosofía); Maurice Godelier (Antropología económica); Jean Piaget (Psicología cognitiva); Pierre Bourdieu (Sociología); sin mencionar los trabajos del "primer" Foucault y los de Lacan, quienes por lo menos parcialmente se ubican dentro del movimiento estructuralista. (Dosse, 1992; Merquior, 1989; Ferry y Renaut, 1985) Pese a la centralidad del estructuralismo en los cincuentas y sesentas, para fines de la década siguiente nadie, fuera de aquellos ubicados en las filas de la Lingüística estructural y la Antropología de Lévi-Strauss, hubiera aceptado ser tildado de "estructuralista.
} 
guroso, él la consideró como mera operación del sistema de la langue (la lengua) por parte de los hablantes y advirtió que el habla no era adecuada para constituir un objeto homogéneo que pudiera ser tratado de manera científica. Complementariamente, Saussure adoptó el enfoque sincrónico, que subsume las consideraciones históricas y temporales en el análisis del aquí y el ahora de la lengua. También expulsó del análisis lingüístico todo referente objetivo, para centrarse en la lengua como sistema auto-contenido de signos arbitrarios al que no le podemos endosar ninguna esencia o cualidad, mucho menos referirlo a un sujeto hablante.

La herencia teórica de Saussure floreció magní́ficamente en la Antropología estructural de Claude LéviStrauss, quien la recibió via Roman Jakobson cuando ambos se encontraban exiliados en los Estados Unidos durante la Segunda Guerra Mundial (Lévi-Strauss y Eribon, 1990). Mediante el análisis del parentesco, los sistemas de clasificación, mitos y arte entre los "primitivos", Lévi-Strauss llegó a la conclusión que el "espíritu humano" opera sobre las bases de oposiciones binarias: caliente / frío, crudo / cocido, ying / yang. No importa si consideramos a un individuo "primitivo" o "civilizado", que viva en tiempos actuales o antiguos, la "mente" es igual para todos los seres humanos. La manera como funciona es determinada por la "naturaleza humana", independientemente de sus manifestaciones fenomenológicas (LéviStrauss, 1962, 1974).

Sin embargo, ni los sistemas de parentesco, ni los mitos y la "lógica de lo concreto" que caracteriza el "pensamiento salvaje", presuponen la figura de un sujeto en su punto de origen:jel "sujeto de la cultura" está totalmente denegado en LéviStrauss! El análisis de las manifestaciones de cultura muestra que estos fenómenos obedecen a su propia lógica, en lugar de responder a la conciencia o voluntad de cualquier sujeto. Más aún, recurrir al sujeto sería un obstáculo para la constitución de las disciplinas sociales como verdaderas ciencias. Con todo rigor, Lévi-Strauss denuncia que las ciencias sociales están atrapadas en la reflexividad y el antropocentrismo, lo que les impide captar los fenómenos al nivel de lo que es invariante, es decir, su estructura (Lévi-Strauss, 1964, 1971). Como lo sostiene en La pensée sauvage, cualquier eventual refundación de las ciencias sociales requeriría adoptar como su objetivo "no constituir al hombre, sino disolverlo", como ya ha ocurrido en las ciencias naturales (Lévi-Strauss, 1962: 326).

Magistralmente, Lévi-Strauss se las ingenió para construir una Antropología sin "antropos" en el centro, y para transformar esta disciplina en una "antropo-lógica" de la mente humana.

En la estela de Nietzsche, Foucault proclamó la inminente "muerte del hombre"... ese simple "pliegue en nuestro conocimiento", esa "invención reciente" de no más de doscientos años, según escribió en Les mots et les choses. Para trazar la genealogía de nuestro familiar I sujeto, Foucault emprendió una vasta investigación en la "arqueología del saber" de Occidente, lo que le permitió establecer que, a diferencia de la la nuestra, no todas las épocas históricas han conferido un lugar central al sujeto. En la edad clásica (que va de mediados del siglo XVII al XVIII) el sujeto no era un dato para ser descrito o pintado, sino más bien una figura elidida del espacio pictórico. De acuerdo a la prescripción de la epistéme clásica, el objeto de la representación debía permanecer invisible, escapando así a toda tentativa de objetivación en la tela ${ }^{5}$. Por eso, Foucault encuentra en el cua-

\footnotetext{
5 Definida de manera sucinta, la epistéme designa al marco de conceptos y nociones epistemológico vigentes en una época que hace posible el conocimiento. En obras posteriores a Las palabras y las cosas, Foucault va a hablar de regímenes de "poder/saber".
}

dro Las Meninas (1656) de Diego Velázquez la metáfora iconológica por excelencia de esta exclusión del sujeto.

En efecto, en este esplendoroso cuadro aparecen pintados varios personajes, y el mismo Velázquez trabajando en su tela. Pero como si fuera algo casual, el cuadro apenas sugiere las figuras de la pareja real española -el tema de la obra- que no se muestran sino reflejadas en un espejo que cuelga ocioso de una pared. De hecho, el rey y la reina están a lo sumo sugeridos en la composición y sus retratos incluso no están claramente logrados, apenas se los adivina en fading (ver Foucault, 1966). Pero, a decir de Foucault, esto no es por un mero capricho del artista, sino porque en la época "no había conciencia epistemológica del hombre como tal". (Foucault, 1966: 320). Dicho de otro modo, lo que está representado en Las Meninas son las funciones de la representación, bien organizadas y ordenadas en el espacio pictórico, pero lo que es suprimido es "el sujeto unificado que plantea estas representaciones" (Dreyfus and Rabinow, 1982: 45).

Según Foucault, hacia 1800 una mutación epistemológica tiene lugar, la cual va a autorizar la emergencia de nuevos temas para el pensamiento y promover una nueva visibilidad de los objetos en el mundo. Situada en el umbral de la modernidad, esta ruptura conduce al desplazamiento del estudio de la producción y la riqueza en la economía al análisis del intercambio y la moneda. Se suplanta la taxonomía por el estudio de los organismos biológicos; $y$, finalmente, se reemplaza el estudio del lenguaje en términos de lógica y representación transparente del pensamiento, por el análisis en términos de historia y convención. La Economía Política de Ricardo, la Biología de Cuvier, y la Filología histórica de Bopp, materializan este cambio epistemológico que inaugura la modernidad. De pronto, De pronto, llas categorías se antropolo- 
gizan y se redefinen como instancias de la analytique de la finitude. En adelante, ocupando el sitio dejado vacante por el rey, "el hombre aparece en su ambigua posición de ser un objeto de conocimiento empírico y un sujeto trascendental que sabe". (Foucault, 1966: 323). Es el comienzo del largo "sueño antropológico"; se inicia así el "interminable monólogo del sujeto". (Paz: 1993: 118).

En el corazón de la genealogía del sujeto moderno, cuya figura más elaborada es la del "sujeto de la sexualidad” (Foucault, 1976, 1984), Foucault sitúa el poder. El sujeto es el producto de "tecnologías del sujeto", "disciplinas", y prácticas de "normalización", que son "modos de objetivación que transforman los seres humanos en sujetos". (Foucault, 1975). Mediante estos dispositivos disciplinarios, el poder ha logrado controlar la libertad de los sujetos, atemperar sus deseos, domesticar sus cuerpos. En suma, Eel sujeto moderno no es, por lo tanto, la creación idílica del humanismo, ni el gentil Golem de la ética de los derechos humanos, sino el efecto inestable de la aplicación de técnicas de poder, control y dominación sobre los individuos y los grupos. Por ello, Foucault afirma que "el objetivo, hoy, no es descubrir quiénes somos, sino rechazar lo que somos", por cuanto lo que somos es en buena parte lo que el poder ha hecho de nosotros. La alternativa, entonces, es "promover nuevas formas de subjetividad mediante el rechazo del tipo de individualidad que se nos ha impuesto". (Foucault, en Dreyfus y Rabinow, 1982: 216).

Sin lugar a dudas, el sujeto fue la bête noire del estructuralismo francés y romper con él era una ruptura estratégica que las disciplinas sociales debían proponerse. La noción misma de "estructura" apuntaba a la expulsión del sujeto fuera de la reflexión social y a cerrar la brecha entre estas disciplinas y las ciencias naturales. Hubo en el estructuralismo una voluntad expresa de abandonar la filosofía de la experiencia, el sentido y el sujeto sostenida por el clan Sartre/Merleau-Ponty, y de reemplazarla con una filosofía del conocimiento, de la racionalidad y el concepto, a la manera de Bachelard, Cavaillès, Koyré y Canguilhem. Este programa, sin embargo, no podía ser llevado a cabo sin críticas en contra de ciertas disciplinas e ideas bien establecidas: v.g., la crítica de Lacan de la "ego-psicología", la posición de Althusser y Balibar en contra del discurso histórico tradicional y el partido tomado por LéviStrauss en contra de la filosofía sartriana de la consciencia. El estructuralismo brindó una esperanza de progreso en la construcción de un discurso científico en las disciplinas sociales renunciando a las actitudes especulativas por mor de ciencia y rigor. Este ethos científico atraviesa la reflexión cimera de un Lacan en Psicoanálisis, de un Greimas en Semántica estructural, de un Dumezil en los estudios de religiones y mitos indo-europeos, de un Claude Lévi-Strauss en Antropología y de muchos otros estructuralistas de primera hora.

\section{Jacques Lacan y el sujeto del significante}

Aunque la posición de Jacques Lacan respecto al sujeto es frecuentemente tomada como otra expresión de la estructuralista "muerte del sujeto", esta ecuación no es de ningún modo exacta ${ }^{6}$. Lacan trató de disipar el malentendido interviniendo luego de la conferencia de Foucault "¿Qué es un autor?” (febrero, 1969. Reproducida en Foucault, 1994) para aclarar que el "retorno a Freud" que él planteaba no tenía que ver con ninguna negación del sujeto. Lo que se proponía era enfocar la subordinación del sujeto al lenguaje y la estructura. Funda-

\footnotetext{
${ }^{6}$ Por cierto, tampoco es válido asimilar el pensamiento de Lacan a un difuso "posmodernismo" como parecen hacerlo los cultural studies en voga en los Estados Unidos, en los que el Psicoanálisis se ve transformado en un ejercicio especulativo disociado de la clínica del analizante que es su fuente.
}

mentar, exactamente, la "dependencia del sujeto con respecto de algo elemental, que nosotros hemos tratado de aislar con el término de 'significante'”, como lo declarara con sus propias palabras (Lacan, 1969: 820). De ningún modo, entonces, para el psicoanálisis lacaniano el tema ha sido el de la supresión del sujeto, sino hacer compatible la idea del sujeto con la de estructura, es decir, el lenguaje. En definitiva, el tópico de la negación del sujeto como tal no podía ser de la incumbencia de Lacan porque, como Bertrand Ogilvie lo señala, "sería como suprimir el objeto mismo de su reflexión, que no es el sujeto tout court sino su reintroducción". (Ogilvie, 1988: 43).

El sujeto en Lacan es concebido como un efecto de la articulación significante. Pura función, mero punto evanescente sin cualidad alguna, salvo aquellas con las que se reviste en el aftermath, en el après coup, de su constitución. No concierne al "ser humano", a la "persona", al "individuo" o a ningún atributo como el ego (moi, yo, self), la identidad, la racionalidad, o el género, adscritos a un particular o a un grupo. No es un dato inicial o empírico, sino un efecto segundo respecto al lenguaje. Contra lo que Althusser sostenía (1965, 1969), el sujeto no es el resultado de las interpelaciones ideológicas que transmutan los individuos en sujetos y tampoco puede ser considerado como la consecuencia positiva del contubernio entre discurso (saber) y poder, a la manera de Foucault. Particularmente, y en contraste con el sujeto de Touraine, el sujeto que Lacan discierne no se reduce a un conjunto de posiciones éticas o tomas de partido respecto a ninguna condición social o política.

Para Lacan, el sujeto tiene su causa en la cadena el significante, lo que nos permite nombrar a dicho sujeto como "sujeto del significante", sujeto determinado y escindido por el significante. Esto no equivale a decir que el significante es el sujeto, como 
si éste fuera simplemente un constructo semiótico. El sujeto como efecto del significante expresa que el sujeto está sujetado al significante, que el sujeto se constituye en el orden simbólico, en el campo del lenguaje y la función de la palabra. En un término: en el Otro?.

Recuérdese que la noción de significante, de cuño saussureano, estaba definida en el Cours como "imagen acústica", mero trazo sonoro diferencial que permitía captar el significado que llevaba aparejado en el interior del signo lingüístico. Lacan se demarca netamente de esta concepción y libera el significante de toda servidumbre con respecto al significado al trazar entre significado y significante una línea (barra) que funciona como barrera a la significación. Dicha barrera impide toda coincidencia término a término entre ambas caras del signo lingüístico, lo cual hace resaltar el aspecto dinámico del significante, en cuanto elemento generador del significado $y$, sobre todo, en cuanto causa de un notable efecto que es el efecto-sujeto. Por eso la definición lacaniana del significante es: "un significante [S1] es lo que representa un sujeto $[\$$, sujeto tachado] para otro significante [S2]". (Lacan, 1960. Reproducido en Lacan, 1966: 835) Tal definición sui-referencial del significante subraya que su función

7 El Otro lacaniano no es simplemente otro nombre del uno: "Es el Otro (Autre) del lenguaje que está siempre ya allí. Es el Otro del discurso universal, de todo lo que ha sido dicho en la medida en que es pensable. (...) Es el Otro de la Biblioteca de Borges, de la Biblioteca total. Es también el Otro de la verdad, ese Otro que es un tercero respecto a todo diálogo, porque en el diálogo del uno y del otro siempre está lo que funciona como referencia, tanto del acuerdo como del desacuerdo (...) El Otro de Lacan es también el Otro cuyo inconsciente es discurso el Otro que en el seno de mí mismo me agita, y por ello es también el Otro del deseo, del deseo como inconsciente, ese deseo opaco al sujeto (Miller, 1979. Reimpreso en Miller, 1986: 18). Obviamente, el Otro así concebido no guarda ninguna relación con el otro que es nuestro semejante, mucho menos con el 'otro generalizado' de G. $H$. Mead, o con lo que Durkheim entendía como 'consciencia colectiva'”. es representar un sujeto, no un significado y mucho menos una cosa..., aunque no ante otro sujeto, sino ante otro significante (Lacan, 1970: 65). De ahllí que el efecto del enjambre significante no sea es ni puede ser la comunicación, la referencia al mundo objetivo, o la supuesta relación intersubjetiva, sino el sujeto mismo. Si el significante representara un sujeto ante otro sujeto, entonces sí sería pertinente hablar de intersubjetividad, pero la función de representación del significante no se ejerce sino ante otro significante.

De manera precisa, el sujeto del significante debe buscarse no en lo que el habl(e)nte (el parlêtre) dice acerca de él en la frase -en lo dicho-, sino en otro lado: en la enunciación -el acto de decir-, que es una dimensión que apunta a los procesos inconscientes que socavan el frágil balance de los enunciados. El sujeto debe ser localizado en ese lugar radicalmente excéntrico que es el inconsciente "estructurado como un lenguaje" en cuanto organizado por la metáfora y la metonimia, mecanismos que Freud presintió en el trabajo del sueño y que él denominó condensación y desplazamiento.

Literalmente, para Lacan el inconsciente es el verdadero sujeto que habla a través del individuo en los momentos reveladores del lapsus, de los sueños, de los actos fallidos e incluso de las palabras, aunque leídas Inter línea. Este efímero e insustancial sujeto del inconsciente irrumpe como algo foráneo y extraño, para de inmediato desaparecer. Como si fuera un instantáneo odestello, poco después de que ingresa en la escena individual, el sujeto se eclipsa detrás de un significante, $\mathrm{S} 1$, que va a representar el sujeto para un significante otro, S2. La serie de sucesos inesperados involuntarios por los cuales el sujeto se manifiesta, nos dice, que este el sujeto siempre está allí (ça parle!), pese a que no lo reconocemos sino cuando una acción perturbadora ocurre e interrumpe nuestra acción y discurso consciente. Esa ruptura en la continuidad significante es lo que caracteriza al sujeto como emergencia del inconsciente.

El sujeto aparece, emerge, entonces, en el campo del Otro como efecto de la articulación significante: sujeto heterogéneo escindido dividido entre dos significantes, formación pasajera efímera carente de toda substancia y de todo ser, por lo que no tiene ningún estatuto (no es un sujeto óntico). Pero por muy fugaz que el efecto sujeto sea, cada cual tiene el deber ético de asumir la responsabilidad de su propia condición subjetiva. De ahí el imperativo freudiano: Wo Es war, soll Ich werden, que Lacan glosa una y otra vez: "là où c'était, là comme sujet dois-je advenir". "Yo debo venir a ser ahí donde fuerzas extrañas -el Otro como lenguaje y el Otro como deseo- una vez dominaban. Yo debo subjetivar tal otredad", según lo vierte Fink (Lacan, 1955. Reimpreso en Lacan 1966: 416; Lacan, 1964: IV; Lacan,1965-1966. Reimpreso en Lacan, 1966: 864; Fink, 1995: 68).

La determinación del sujeto por la estructura significante no lo lo dispensa, de ningún modo, de su de su responsabilidad individual, de de la adopción de una posición subjetiva frente a la plusvalía de goce que le proporcionan sus síntomas (es decir, su forma de gozar del inconsciente). De hecho, Para su gracia o desgracia, el sujeto ni siquiera puede contar con el beneficio de la ignorancia o la buena fe para atenuar su responsabilidad ética por sus acciones como sujeto particular, como miembro de la comunidad, como sujeto que vive en sociedad con otros sujetos. Por muy leve e ingrávida que sea su condición, el sujeto no es, ni mucho menos, el títere dócil de las estructuras, aunque fuera del orden significante no sea nada más que un simple substrato material: "una libra de carne", 
para decirlo con una expresión de Lacan $^{8}$.

Sin embargo, apuntar al significante como la causa del sujeto implica asumir que desde su origen el sujeto es constituido con/por una falla estructural: algo le falta para estar "completo" y eso le impide ser "total", holístico, indiviso e igual a sí mismo. Esa falla, ese pathos, constituye estructuralmente al sujeto; sin ella sería apenas un autómata que nunca yerra, que no se equivoca ni sueña, como la estúpida computadora con la que escribo.

Que el sujeto tenga su causa en el significante, no niega el hecho de que éste se produce en el ser vivo. Aunque carente de todo rasgo o característica esencial, el sujeto no es una construcción meramente semiótica o psíquica, ni tampoco semiológica. Es un efecto del lenguaje en un ser vivo que tiene un cuerpo $\mathrm{y}$, por lo tanto, sexualidad..., en la medida en que la sexualidad es un efecto del significante en el cuerpo (o mejor: en el organismo). Como cuerpo, el sujeto alcanza su unidad pasando por el "estadio del espejo", el cual modela el registro Imaginario de la estructura subjetiva, el registro del yo y del otro (Lacan, 1949). Esta dimensión siempre está articulada con la del Simbólico, el lenguaje, y con el Real, resto que escapa a la simbolización. El anudamiento de estos tres registros, Real, Simbólico e Imaginario, da cuenta de la estructura del sujeto y de las múltiples dimensiones de la realidad en la que ésta se encuentra involucrado.

Obviamente, del sujeto del psicoanálisis no se puede decir que se agota en la epistéme moderna, como Foucault lo pensaba, porque no es la alianza disciplinaria entre saber y poder la que puede dar cuenta del

\footnotetext{
${ }^{8} \mathrm{O}$, si se quiere, un subjectum o suppositum -el hypokeimenon de los Griegos- donde el sujeto es una mera hipóstasis, una ousia (substancia), pero no un sujeto en el sentido moderno, que es el del ego cogito.
}

arco completo de su constitución subjetiva. Desde el punto de vista del psicoanálisis, hay que entender que el sujeto es justamente el efecto que elude esta alianza, como lo explica muy bien Slavoj Zizek (1998: 78), porque el sujeto es un suceso inesperado que subvierte el eje del poder y el saber epistémico formal puesto en discurso.

Finalmente, señalaré que el sujeto del inconsciente, aunque enteramente singular y único, no puede ser visto como una entidad solipsista, autista. El sujeto es un efecto del lenguaje y el lenguaje es lo que hace eminentemente social nuestra condición humana, no simplemente dotada de un instinto gregario como el de las abejas y las hormigas. El lenguaje es el Otro de la cultura de donde vienen los significantes que constituyen al sujeto. Operando como discurso, el lenguaje instituye la sociedad porque es el discurso el que crea lazos entre los individuos y establece lo social como dominio de intercambio simbólico ${ }^{9}$.

\section{Alain Touraine: el sujeto elusivo de la sociedad}

Es paradójico que Touraine apelara al iniciara el despliegue de sus ideas sobre el sujeto como actor colectivo y movimiento social cuando la

\footnotetext{
${ }^{9}$ La mínima expresión de un lazo social es aquel en el que un individuo se dirige a otro. La propiedad intrínseca del acto discursivo es ser vinculante (aunque no necesariamente "comunicacional"), en el sentido de que siempre implica a dos. El discurso establece la estructura del nexo social porque asigna el lugar a ocupar por quienes están así conectados, organizando y haciendo posible la acción social. Estos lugares asimétricos son independientes de las características y propiedades particulares de los individuos; no corresponden a los tradicionales figuras de emisor/receptor de la comunicación, sino más bien a los del agente del discurso y del otro. El discurso va más allá del hecho ocasional de pronunciar palabras y frases pues no se reduce al acto de habla, a la creación de sentido, o a la comunicación. Apunta, más bien, a las relaciones invariantes, aunque no complementarias, que la operación del lenguaje establece entre individuos, lo cual condiciona desde el principio el nexo que unos establecen con otros, aun sin que se haya pronunciado palabra alguna (Ver Lacan, 1969-1970: 11).
}

mayor parte de la intelligentsia francesa, reunida bajo la bandera del estructuralismo, anunciaba la inminente "muerte del sujeto". De hecho, para Touraine el recurso al sujeto es un partido tomado en contra de la anulación de la acción social y la individualidad por la determinación estructural.

Como leitmotif teórico que atraviesa su pensamiento, el tema puede detectarse tan temprano como1977, aunque por aquel entonces previamente se encontraba integrado en la consideración más amplia de la producción de la sociedad por actores que se confrontan unos con otros por el control del "sistema de acción histórica”. (Touraine, 1973). De manera inconfundible, desde su libro Le retour de l'acteur (del que el autor dice "debió haberse titulado 'el retorno del sujeto'", 1984: xxv), hasta sus más reciente producción (Critique de la modernité, 1992; Qu'est-ce que la démocracie, 1994; Pourrons-nous vivre ensemble?, 1997; La recherche de soi: dialogues sur le sujet, 2000), el sujeto es el protagonista absoluto de la Sociología de Touraine, en la cual se ha tallado un estatuto de actor "colectivo" o "social". (Dubet y Wieviorka, 1995; Clark y Diani, 1996).

Al igual que otras categorías que forman el andamiaje conceptual de su pensamiento -movimiento social, historicidad, sociedad programada-, "sujeto" no es una palabra casualmente proferida que vendría a disfrazar nociones vulgares o a recubrir realidades empíricas. Es, por el contrario, una herramienta heurística, un recurso heurístico, una verdadera elaboración conceptual. Como "sujeto", Touraine no tipifica la inscripción social de los individuos mediante la incorporación de roles -su socialización-, ni tampoco la "construcción social" de la subjetividad, sino que plantea que individuos y grupos se convierten en sujetos en el conflicto por el control de las orientaciones normativas de la vida social, que 
son las que definen la "historicidad"10.

El sujeto, para Touraine, es ante todo una forma de relación del individuo, o del movimiento social, consigo mismo. Esa, condición no es dada de por sí de por si, sino que, por el contrario, implica una conquista, un incesante trabajo de individuación y de vigilancia sobre sí mismo. No es una adquisición de por vida, puesto que la amenaza de desubjetivación pende constante sobre el sujeto: la anomia del mercado o de la droga, del consumo, el hedonismo de la vida contemporánea, la disolución del yo en la comunidad y la norma social; en una palabra, la despersonalización. Habiendo perdido los garantes metasociales que tradicionalmente lo sostenían como individuo (la religión, la razón, la comunidad, la sociedad, el estado, la historia), el sujeto sólo puede fundarse en su "yo" -que Touraine distingue cuidadosamente del "ego", el moi social, el me de G. H. Mead-, desde donde será capaz de reconocer al otro como No es sino a partir que de la condición de sujeto que es posible reconocer al otro como mi semejante, es decir, como sujeto él también. Sin ser una entidad psicológica, en última instancia, para Touraine el sujeto es "un Yo (Je), un intento por decir Yo, con pleno conocimiento de que la vida personal está dominada, por un lado, por la libido y el "ello" (Id), y por el otro, por los roles sociales" (Touraine, 1995: 209). La condición de sujeto, sin embargo, no es una adquisición de por vida puesto que la amenaza de desubjetivación amenaza en

\footnotetext{
${ }^{10}$ La "historicidad" es el telón de fondo de las prácticas de los movimientos sociales. El concepto difiere claramente del de "historia", porque mientras que "historia" remite a la dirección de los cambios en el tiempo, "historicidad" especifica "al conjunto de modelos culturales que gobiernan las prácticas sociales ... a través de las relaciones sociales" (Touraine, 1984). En palabras de Alberto Izzo, la historicidad no es simplemente el contexto histórico concreto en que se desenvuelven la lucha entre los actores sociales, sino la "capacidad de lo social de constituirse de manera autónoma”. (Izzo, 1985: 160).
}

permanencia sobre el sujeto: la anomía del mercado o de la droga, del consumo, el hedonismo de la vida contemporánea, la disolución del yo en la comunidad y la norma social, etc.

Más aún, en estricto sentido Touraine formula el sujeto en términos de un discurso ético-político sobre el individuo y los procesos sociales en que se inserta, particularmente, sobre los movimientos sociales característicos de las sociedades industriales y post-industriales, que él prefiere llamar "programadas". (Touraine, 1995). El referente de Touraine es, de plano, es una ética de valores individuales cuyos acentos recuerdan el pour-soi sartreano. En este sentido, Touraine escribe:

Llamo sujeto..., al deseo de ser un individuo, de crear una historia personal, de otorgar sentido al conjunto de las experiencias personales. (...) Vivir su vida, encontrarle un referente que pueda dotarla de sentido, más que pertenecer a una categoría social o una comunidad de creyentes (Touraine, 1995:29).

\section{Y también:}

Ser sujeto es primeramente hacer de mi vida un proyecto de vida, de tal forma que mi proyecto gobierna mi vida, no la serie contingente de hechos. (...) El asunto es tomar la vida personal en manos, ... tener la capacidad de producir, no simplemente consumir, la existencia (Touraine, 1993a: 28).

En efecto, el sujeto que Touraine coloca en el centro de la "producción de la sociedad" es un postulado ético válido para individuos y para grupos, no exactamente una categoría social. Aunque el sujeto se manifiesta y se constituye en las prácticas sociales, en sí no es una forma social ni un hecho positivo, sino "un principio no-social sobre el que reposa la organización de la sociedad". (Touraine, 1996: 301).

Lo que sorprendente de esta concepción, sin embargo, reside esen el hecho de que luego del largo apogeo de la explicación de "lo social por lo social" (según reza el postulado durkheimiano), Touraine voltea la página para reconocer "que lo social reposa en lo no-social y no puede ser definido de otra manera que por el lugar que le otorga o le niega a este principio no-social que es el sujeto". (Touraine, 1997: 89). Esto quiere decir que la finalidad de la acción social no es la sociedad misma, como postulaba la sociología clásica, sino el sujeto liberado de las ataduras que limitan su acción: la comunidad, la tradición, las redes sociales, etc. En Congruencia con esta te con esta visión, posición, en la metodología de intervención que propone, Touraine rompe con el tradicional objetivismo sociológico, cuyo foco es la determinación estructural por condiciones materiales "objetivas" y en su lugar, subraya la acción de actores movidos por valores culturales, que por definición no son objetivos. A partir de ahora, la Sociología se enfocará claramente en un tipo particular de hecho social: las relaciones sociales, no más en las situaciones objetivas, en las intenciones, las opiniones o el sentido con que los actores racionalizan sus prácticas. A fortiori, la posición de Touraine desemboca en una seria interrogación sobre si "sociedad" es todavía un concepto útil, o incluso si la sociedad como tal existe. (Touraine, 1980; 1993). visto que "todos los sectores de la vida social se han independizado" (Touraine y Khosrokhavar 2000: 297). y que, por consiguiente, el campo social no presenta más ninguna unidad fundamental, ninguna solidaridad cohesiva.

Según Touraine, si hay "actores sociales" que producen situaciones y asumen posiciones en posiciones en conflicto es porque hay sujetos, no lo opuesto. De ahí que ser sujeto sea la condición para que grupos e individuos se planteen como actores autónomos de sus vidas. A diferencia de los "agentes" sociales a los que alude Bourdieu (1972, 1994), los sujetos-actores no reaccionan según las determinaciones del campo en que se desenvuelven, ni mucho menos actúan de manera me- 
cánica según la posición que ocupan en la estructura social; por el contrario, los actores, sino que producen creativamente la sociedad. No se comportan en respuesta a situaciones, sino que crean situaciones al actúuanr contra los roles sociales y las limitaciones impuestas por la comunidad, el mercado o la tecnología. Esto no quiere decir que los actores se confronten en un espacio social vacío, o que lleven a cabo sus prácticas fuera de la estructura social, pero Touraine entiende el término estructura como una propiedad de la actividad, del movimiento de los actores en sociedad colectivos, no como repertorio de posible acciones o como sistema funcional de posiciones, relaciones y restricciones a la acción del sujeto.

Touraine considera que la condición de sujeto, y por lo tanto, la de actor social, no es sino la más alta expresión del grado de historicidad alcanzado por una sociedad. Legado por excelencia de la modernidad, el sujeto nunca antes logró tal autonomía y nivel de realización como en las "sociedades programadas", lo cual se manifiesta en el hecho de que aquí los movimientos sociales representan al sujeto colectivo ${ }^{11}$.

En efecto, Touraine caracteriza estos los movimientos sociales por reivindicar el derecho a la creatividad, la realización de los proyectos personales y la libertad de comunicación. También porque se erigen en contra de la racionalización a ultranza que acarrea el desarrollo del capitalismo, que amenaza al propio sujeto y su calidad de vida (Touraine,

\footnotetext{
11 Touraine se opone a considerar como "movimiento social" a cualquier acción colectiva. En su criterio, los movimientos sociales propiamente dichos "oponen actores sociales entre sí: 1) por el control de los recursos más importantes de una sociedad, o 2) por el control del proceso histórico de transformación de esta sociedad. Un movimiento social es un conflicto entre grupos sociales que va más allá de una lucha de intereses y pone en tela de juicio un sistema de poder. Lo que también supone una referencia positiva a las orientaciones culturales de una sociedad". (Touraine, 1997; Touraine, 1985).
}

1992). Dados estoos rasgos, rasgos, resulta claro que los movimientos sociales contemporáneos contrastan en sus plataformas con los tradicionales reclamos de los movimientos sociales de la sociedad industrial (v.g., el movimiento de los trabajadores), mucho más restringidas a las demandas económicas ${ }^{12}$.

En tanto tomados como sujetos colectivos, los "nuevos movimientos sociales" se distinguen por su voluntad de ser, la que se afirma como resistencia cultural, lucha política y esfuerzo por desembarazarse de la tradición comunitaria y demás determinaciones que podrían restringir su libertad de decisión y acción. Es por eso que en nuestros días el sujeto adopta la figura emblemática del anónimo disidente chino que detuvo los tanques de guerra en la plaza Tiananmen de Pekín, en junio de1989, afirmando con su soberbio acto que su condición subjetiva no podría ser doblegada por la represión política. Con toda lógica, Touraine afirma que la democracia es el modelo político que más conviene al sujeto y a su reconocimiento; según su consideración, una democracia de contenidos y no meramente formal propenderá siempre a la eclosión de sujetos en el seno de la sociedad civil y al fortalecimiento del espacio público de deliberación (Cf. Touraine, 1994).

Así concebido, es claro que el sujeto teorizado por Touraine se diferencia de aquellas figuras de cera del histriónico individuo del pragmatismo, para quien la acción es un mero rol en la commedia dell'arte de la vida social. Tampoco se confunde con el actor siempre alerta de la fenomenología, presto a la construcción racional del sentido del mundo de la vida. Touraine no toma por evidente la condición de actor, sino que desarrolla una teoría para sostener-

\footnotetext{
12 Por esa razón, y para marcar claramente diferencias, se suele emplear el calificativo de "nuevos" al eso explica porqué hablar dese suele llamar "nuevos" a los movimientos sociales contemporáneos.
}

lo como categoría del análisis sociológico. Por esa vía viene a concebir un sujeto propiamente sociológico: el movimiento social en tanto expresión de un subjetividadjeto colectivo.

\section{Conclusiones}

Es inútil buscar en los ensayos de Sociología o Ciencia Política contemporánea una caracterización no funcionalista del actor, en que este no se capte a partir de su rol en los procesos sociales o de la finalidad de su acción. Con frecuencia el "actor" que mencionan los textos y ensayos es tomado como un hecho empírico, substancia dada a la percepción, fenómeno entre fenómenos del mundo social, que no requeriría construcción teórica alguna. También, por los tiempos que corren en el pensamiento sociológico, encontramos ael actor se encuentra "entificado" como "agency," o como término en una "red" en la que se movilizan recursos materiales, acceso a poder, capitales simbólicos, etc. No es raro, además, que aparezca travestido en narrativas que subrayan identidades sociales o políticas, las que apuntan en definitiva a hechos de sentido, aunque éstos, desde un punto de vista psicoanalítico, son justamente los que eluden al sujeto.

Es obvio que una Sociología que entienda el proceso social como acción y conflicto entre desplegada por los actores, grupos presenta un vacío fundamental si no posee una teoría sistemática del actor en sociedad. Una explicación de ese género tendría que evitar reducir los actores a la condición de "agentes" del sistema, tanto como rehusarse a subsumirlos en la acción racional, utilitaria, o comunicativa. Más aún, tendría que negarse a entenderlos como cínicos figurantes que representan un papel en un escenario.

Para llenar el vacío en el pensamiento sociológico de una teoría del actor, sería imperativo anclar la explicación en una teoría del sujeto que esté radicalmente divorciada de toda 
visión intuitiva o pragmática. Allílí radica, precisamente, la importancia del esfuerzo de Touraine, quien con su propuesta de "sujeto colectivo / actor social" se inscribe en contra de tal limitación y en contra de la tentación funcionalista de definir al actor por su rol en las acciones colectivas. De paso, Touraine ha sentado los fundamentos de un discurso propiamente sociológico sobre el sujeto, no simplemente una reflexión filosófica, psicológica o política acerca de la condición subjetiva de individuos o grupos que viven en sociedad. Por eso hay que reconocer el esfuerzo de Touraine como un intento decisivo en la construcción del "sujeto de la Sociología".

Sin embargo, el retorno del sujeto como actor y movimiento social actor colectivo que Touraine propone parece anunciar la vuelta del sujeto transparente a sí mismo y a su conciencia reflexiva, aunque lograda esta vez en la lucha social. Se trata del regreso del sujeto de la voluntad, adornado con cualidades transcendentales frente a sus determinaciones históricas y sociales, limitado solo por su propia acción. De la reintegración del sujeto unificado por su "yo", que asume las circunstancias de su vida como individuo autónomo y soberano, como actor libre capaz de definir los términos de su propia inserción en la historicidad. Es este un sujeto consciente de su condición de individuo, que lucha por el reconocimiento de su identidad y cuya política es el liberalismo y la democracia. Tal sujeto, para concluir el largo catálogo de sus virtudes, no es quizás otro sino el sujeto sartreano de la creatividad, la dignidad y la libertad.

La ética con la que Touraine fundamenta el sujeto de la sociedad traslada, a lo colectivo algunos principios y valores que pertenecen ante todo a los individuos. Este es un aspecto muy problemático de su concepción, pues sitúa una contradicción en el corazón de una teoría que clama para sí el crédito de ser una baza en contra del individualis- mo metodológico, el cual explica la sociedad como una simple adición de unidades. Podríamos más aún preguntarnos porqué sería indispensable sustentar en postulados de valor éticos la formulación de un sujeto sociológico, como Touraine lo hace. Un discurso ético no necesariamente conduce a formular un sujeto, como lo demuestran los griegos clásicos, quienes desarrollaron una cuidadosa ética del "cuidado de sí" aunque no poseían el equivalente conceptual de nuestro familiar sujeto: de hecho, el sujeto como tal era desconocido en Grecia (ver Foucault, 1976, 1984; Vernant, 1992).

Subrepticiamente, Touraine transpone el registro individual en el colectivo, con lo que en última instancia su concepción del movimiento social como actor y sujeto viene a ser una imagen amplificada del individuo que se desenvuelve en sociedad. En esa medida, hablar de los grupos como actores o sujetos es usar una simple analogía, una expresión metafórica no necesariamente feliz. No obstante, en su Critica de la Modernidad, Touraine sostiene para su descargo que "no hay opción entre lo individual y lo colectivo, sino entre la producción de la sociedad y su consumo, entre la libertad y los determinismos sociales, en tanto que una como los otros se manifiestan por igual en el nivel de las conductas individuales y en el de la acción colectiva". Pero aún admitiendo tal cosa, esto, subsiste todavía el imperativo lógico de establecer diferencias entre el sujeto, que siendo social es a la vez único, y lo propiamente colectivo, que no posee tal carácter de singularidad y está regido por efectos imaginarios de grupo (identificación).

El sujeto del psicoanálisis revierte, subvierte, el sujeto sociológico de Touraine, al situar un sujeto dividido por el lenguaje, siempre otro, pulsátil e inestable. Este sujeto no puede fundarse en su conciencia, porque su conciencia está perturbada por el deseo, por el goce pulsional que lo empuja a buscar y repetir la satisfacción inconsciente, aún pagando el precio de su neurosis ${ }^{13}$. De parte a parte un saber habita este sujeto, un saber no sabido por su entendimiento, que existe y que es tan propio que no vale para otros. No se trata, entonces, de un saber formal y discursivo, de un saber-semblante: se trata del saber de una verdad (en minúsculas), la del sujeto, la verdad de lo no realizado del deseo inconsciente. Un sujeto así no puede parapetarse en su "ego", porque su "yo" es ante todo alienación especular. De ahí que no se le pueda prescribir dosis repetidas de "autoestima" y reconocimiento social, so pena de reforzarlo en su íntima méconnaissance.

Es quizá la búsqueda por fundamentar un imposible sujeto plural colectivo lo que da al traste con el esfuerzo de sustentar un sujeto de la Sociología. No es posible tal sujeto colectivo porque no hay enunciación colectiva. Al sujeto le basta con ser social porque los elementos de su constitución le vienen del Otro y porque se desenvuelve en relaciones sociales que son producto del discurso (el discurso es lo que hace lazo social entre sujetos, no la soli-

\footnotetext{
${ }^{13}$ Para el psicoanálisis el "deseo" se distingue claramente de la "necesidad" y de la "demanda". Las necesidades pueden encontrar satisfacción adecuada en un elemento del mundo exterior, como el hambre en los alimentos, la sed en el agua, etc.; el deseo, por el contrario, es indestructible porque es fundamentalmente nostalgia por algo que no ya no tenemos, que hemos perdido para siempre. El deseo apunta a una experiencia primordial de satisfacción que ha dejado trazas mnemónicas en la psiquis inconsciente y que quisiéramos revivir mediante los sustitutos que podamos encontrar en la realidad circundante (desde los objetos de consumo hasta las parejas sexuales). Desafortunadamente, todo acceso a esta experiencia original está cerrado para siempre por que nuestras posibilidades de satisfacción dependen ahora del lenguaje. En la medida que el deseo tiene que pasar por la demanda articulada, se pierde y deja fuera lo esencial, que es precisamente el objeto que nos falta y que buscamos desesperados a través de la demanda. Este objeto de satisfacción, más allá de cualquier demanda, se ubica entonces del lado del inaccesible Real: se trata del "objeto a", que es a la vez el objeto que causa el deseo y objeto mismo del deseo.
} 
daridad mecánica u orgánica entre los individuos, como creía Durkheim). El sujeto nNo requiere disfrazarse de sujeto colectivo, porque lo que es colectivo no es una condición de la subjetividado, sino de los medios por los cuales un sujeto los sujetos se identifican con otro, se vuelve en cierta medida "igual" al otro, como lo señalaba apuntaba Freud en Psicología de Masas y Análisis del Yo. El efecto sujeto es único en cada caso, nunca fenómeno de masa. La reiterada confusión entre lo colectivo y lo social oscurece el discernimiento de la especificidad de cada instancia: lo social propiamente dicho es el lenguaje, el gran Otro de la cultura que es el acervo de significantes que fundan la sociedad humana como comunidad de hablantes (registro Simbólico); mientras que lo colectivo es lo que nos hace uno con otros, aquello que nos establece como comunidad de semejantes (registro Imaginario): el idioma, la nacionalidad, el nombre de la familia a la que pertenecemos.

Considerados estos elementos, podemos ahora intentar un primer paso hacia una la caracterización alternativa del actor como un sujeto-individuo que ha sido investido de legitimidad simbólica para declarar como problema tal o cual aspecto del entorno social ${ }^{14}$. Al sujeto esta investidura le le viene al sujeto desde el grupo, quien se se la otorga de una manera formal, como cuando los ciudadanos eligen su presidente mediante el voto, o cuando es investido por un representante institucional legítimo (un ministro es nombrado por el presidente, un cardenal por el papa); o de manera informal, como en los casos de liderazgo de facto. Una vez que ha recibido el mandato simbólico, el sujeto el sujeto puede asumirse como

14 Una "declaración" es un típico acto performativo (o acto de habla). Por medio de una declaración un juez puede absolver de cargos a un acusado, o un presidente inaugurar una sesión de su gabinete (Ver Austin, 1962; Searle, 1969). actor (y ser reconocido) como tal por otros actores "actor" social y político. Plantearse como "actor de la sociedad", entonces, sería para el sujeto asumir una posición respecto a un I mandato recibido, sin que esto anule su "falta en ser" de sujeto sujetado al lenguaje y a su efecto de inconsciente. No hay, ni puede haber, "actor total", indiviso soberano amo de sí mismo, cuya subjetividad no esté descentrada por el goce inter-dicto de la pulsión que se aloja en las oquedades de su cuerpo.

El mandato simbólico que el actor recibe le otorga legitimidad para acarrear hasta el espacio público, espacio de representación pública, las demandas individuales de los miembros del grupo, estatuyéndolas como demandas colectivas, como problemas sociales que eventualmente van a ser procesados por las políticas públicas. Sin duda, cCon sus actos de habla los actores configuran el espacio colectivo aunque sus prácticas se realizan en un marco que los constriñe porque allí están presentes otros actores, diferenciados por cargas desiguales de poder y distintas capacidades simbólicas. Si bien la opción de rechazo a tal o cual posición discursiva es siempre una posibilidad del actor, eso mismo nos reitera que las prácticas de la sociedad nunca están más allá del lenguaje y el discurso. Por lo demás, al declarar tal o cual un hecho como "problema", el actor le otorga una calificación, lo cual a cual fomenta cierta visibilidad y determinada lectura de lo social, lo que, a su vez, promueve tipos particulares de nexos entre actores en la sociedad civil.

Para concluir, diría que si la Sociología apunta a construir su sujeto tiene necesariamente que ampararse en una teoría del lenguaje que no sea de tipo únicamente formal (como la de la Lingüística), pues sólo así se capta que el efecto de la articulación significante tiene como efecto es un sujeto. Tal vez la teoría sociológica pueda encon- trar esos elementos en el vasto fondo conceptual del Psicoanálisis lacaniano.

\section{Bibliografía}

Althusser, Louis. Pour Marx. París: Maspero, 1965.

Maspero, 1969

Austin, J. L. How to do Things with Words. Cambridge: Harvard University Press, 1962.

Berger, Peter y Luckmann, Thomas. The Social Construction of Reality. Garden City: Doubleday, 1966.

BLUMER, Herbert. Symbolic Interactionism, perspectives and method. Englewood Cliffs, N.J: Prentice-Hall, 1969.

Bourdieu, Pierre. Esquisse d'une théorie de la pratique. Précédée de trois études d'ethnologyie kabyle. Genève: Droz 1972.

- Raisons pratiques: sur la théorie de l'action. Paris: Seuils, 1994.

Clark, Jon y DianI, Marco (editores). Alain Touraine. London-Washington D.C.: Falmer Press, 1996.

Cooley, Charles Horton. Human Nature and the Social Order. New York: Shoken Books, 1964.

Dosse, François. Histoire du structuralisme, 2 volumes, Paris: Editions La Découverte, 1992.

Dreyfus, Hubert y Rabinow, Paul. Michel Foucault: Beyond Structuralism and Hermeneutics. Chicago: The University of Chicago Press, 1982.

Dubet, François y Wieviorka, Michel (editores). Penser le Sujet, autour d'Alain Touraine, Colloque de Cerisy, Paris: Fayard, 1995.

Eidelsztein, Alfredo. El grafo del deseo. Buenos Aires: Manantial, 1995.

Ferry, Luc, y Renaud, Alain. La pensée 68: essai sur l'anti-humanisme contemporain. Paris: Gallimard, 1985.

FINk, Bruce. The Lacanian Subject, between Language and Jouissance. Princeton, N.J: Princeton University Press, 1995.

Foucault, Michel. Les mots et les choses. Paris: Gallimard, 1966. 
(1966a) "L'homme est-il mort?" Dits et écrits. Paris: Gallimard, 1994.

(1969) "Qu'est-ce qu'un auteur". Dits et écrits. Paris: Gallimard, 1994.

Surveiller et Punir. París: Gallimard, 1975.

Histoire de la Sexualité. Vol. I. La volonté de savoir. Paris: Gallimard, 1976.

Histoire de la Sexualité. Vol. III, Le souci de soi, Paris: Tel, Gallimard, 1984.

Goffman, Erving (1959) The Presentation of Self in Everyday Life. Woodstock, N.Y. Overlook Press, 1973.

Izzo, Alberto. "Recensione a Alain Touraine, Le retour de l'acteur". La critica sociológica, 74 (estate 1985), Roma: aprilegiugno, 1985.

LACAN, Jacques. (1949) "Le stade du miroir comme formateur de la fonction du Je". Reproducido en Ecrits, Paris: Seuil, 1966.

(1955) "La chose freudienne, ou Le sens du retour à Freud en Psychanalyse". Reproducido en Ecrits, Paris: Seuil, 1966.

(1958) "La signification du phallus". Reproducido en Ecrits, Paris: Seuil, 1966.

(1960) "Position de l'inconscient". Reproducido en Ecrits, Paris: Seuil, 1966.

(1964) Le Séminaire XI, Les quatre concepts fondamentaux de la psychanalyse. Paris: Seuil, 1973.

(1965-1966) "La science et la verité". Reproducido en Ecrits, Paris: Seuil, 1966.

(1969) "Intervention" en la conferencia "Qu'est-ce qu'un auteur" de Michel Foucault. Reproducido en Dits et Ecrits, Paris Gallimard, 1994.

(1969-1970) Le Séminaire XVII, L'envers de la psychanalyse. Paris: Seuil, 1991.

(1970) "Radiophonie". Scilicet, N 2/3. Paris: Seuil, 1970.

LACLAU, Ernesto. Emancipations. New York and London: Verso, 1996.

LeVI-Strauss, Claude. La pensée sauvage. Paris: Plon, 1962.

Mythologiques I: Le cru et le cuit. Paris: Plon, 1964.
Mythologiques IV: L'homme nu. Paris: Plon, 1971.

Plon, 1974

Anthropologie structurale I. Paris:

Con Didier Eribon. De près et de loin. Paris: Points, 1990.

Mead, George H. (1934) Mind, Self, and Society from the Standpoint of a Social Behaviourist. Chicago: University of Chicago Press, 1962.

Merleau-Ponty, Maurice. Les aventures de la dialectique. Paris: Gallimard, 1955.

Merquior, Joao G. De Praga a Paris: crítica del pensamiento estructuralista y postestructuralista. Mexico: FCE, 1989.

Miller, Jacques Alain. "Conferencias Caraqueñas". Recorrido de Lacan. Buenos Aires: Manantial, 1986.

NANCY, Jean-Luc (editor). Who Comes After the Subject? New York and London: Routledge, 1991.

OGILVIE, Bertrand. Lacan, le sujet. Paris: PUF, 1988.

Parsons, Talcott. The Structure of Social Action. Glencoe: The Free Press, 1937.

PAZ, Octavio (1967) Lévi-Strauss o el nuevo festín de Esopo. Barcelona: Seix Barral, 1993.

PoMmier, Gérard. Freud apolitique? Paris: Champs-Flammarion, 1998.

Saussure, Ferdinand de (1916) Cours de Linguistique Générale. Paris: Payot, 1980.

Schütz, Alfred (1932) The Phenomenology of the Social World. Evanston, III: Northwestern University Press, 1967.

Sennett, Richard. "Foreword", to Alain Touraine's The Voice and the Eye. Cambridge: Cambridge University Press, 1981.

SEARLE, John. Speech Acts: an essay in the philosophy of language. London: Cambridge University Press, 1969.

Touraine, Alain. (1973) Production de la société. Paris: Seuil, 1993.

. "L'inutile idée de société". Robert Maggiori et Christian Delacampagne (eds). Philosopher. Paris: Fayard, 1980

Fayard, 1984.
."The Study of Social Movements". Social Research, vol. 52, N. 4, New York: New School for Social Research, winter 1985.

Critique de la modernité. Paris: Fayard y Livre de Poche, 1992.

"Is Sociology Still the Study of Society?" Thesis Eleven Reader: Between Totalitarianism and Postmodernity. Peter Beilharz, Gillian Robinson y John Rundell (editores). 1993.

. "Le suject comme mouvement social ou la critique de la modernité". Aspects Sociologiques. Sainte Foy, Québec. Vol. 1, No. 3, Décembre 1993a.

- Qu'est-ce que la démocracie. Paris: Fayard, 1994.

"La formation du sujet". Dubet, François y Michel Wieviorka (editores). Penser le Sujet, autour d'Alain Touraine, Colloque de Cerisy, Paris: Fayard, 1995.

"A Sociology of the subject". Clark, Jon y Marco Diani (editores). Alain Touraine. London-Washington D.C.: Falmer Press, 1996.

Pourrons-nous vivre ensemble? Egaux et différents. Paris: Fayard, 1997.

"De la mañana de los regímenes nacional-populares a la víspera de los movimientos sociales". Miami: LASA, otoño de 1997a.

Comment sortir du libéralism? Paris: Fayard, 1999.

Con Farhad Khosrokhavar. La recherche de soi: entretiens dialogue sur le sujet. Paris: Fayard, 2000.

Vernant, Jean Pierre. "De la psychologie historique à l'anthropologie de la Grèce ancienne". Weil, Dominique (editor). Homme et Sujet: la subjectivité en question dans les sciences humaines, Paris: Ed. L'Harmattan, 1992.

ZIZEK, Slavoj. "Four Discourses, Four Subjects", in Zizek, Slavoj y Renata Salecl (editores). SIC 2: Cogito and the Unconscious. Durham and London: Duke University Press, 1998. 